\title{
2-hydroxy-4-amino-azobenzene modified Graphene Oxide with Incorporation of Bilirubin Oxidase for Photoelectrochemical Catalysis of Oxygen Reduction Reaction
}

\author{
Xueqing Chu, Mi Zhang, Wenshan Huo, Han Zeng*, Yang Yang \\ Xinjiang key laboratory of energy storage and photoelectrocatalytic materials, Chemistry and \\ Chemical Engineering Academy, XinJiang Normal University, Urumuqi 830054, XinJiang Uyghur \\ autonomous region, People's Republic of China \\ *E-mail: zenghan1289@163.com
}

doi: $10.20964 / 2020.11 .46$

Received: 25 July 2020 / Accepted: 8 September 2020 / Published: 30 September 2020

\begin{abstract}
Bilirubin oxidase (BOD) molecules were firmly tethered on the surface of graphene oxide (GO) functionalized with 2-hydroxy-4-amino-azobenzene (AZO-1). Further, a BOD-based electrode was prepared through the immobilization of enzyme on the nanocomplex via drop casting. The morphology, structural properties, surface chemistry, and physiochemical features of the prepared nanocomplex were investigated by microscopic, spectrometric, electrochemical, and other characterization techniques. The as-prepared nanocomplex with enzyme incorporation exhibited high loading amount of redox protein molecule, excellent mechanical robustness, and thermal stability. The complicated mutual interaction between the nanocomplex and protein molecules led to a partial ordered conglomeration of enzyme molecules with micelle-like surface characteristics. The combination of cofactors within BOD and AZO-1 formed a composite with significantly suppressed fluorescence emission and inferior capability of electron transportation. Direct charge transfer in BODbased electrode could be achieved with redox group of GO as the primary electroactive site. A considerable negative impact on the efficiency of electron transport, turnover frequency of substrate conversion, and incident light utilization for this redox-protein-based electrode was verified. However, the as-prepared BOD-based electrode exhibited high affinity to oxygen molecules, and the oxygen binding was not hampered severely in the presence of ligation between adjacent heteroatoms within AZO- 1 and $\mathrm{T}_{1}$ site in BOD.
\end{abstract}

Keywords: 2-hydroxy-4-amino-azobenzene, graphene oxide, bilirubin oxidase, photoelectrochemical catalysis, oxygen reduction reaction

\section{FULL TEXT}


(C) 2020 The Authors. Published by ESG (www.electrochemsci.org). This article is an open access article distributed under the terms and conditions of the Creative Commons Attribution license (http://creativecommons.org/licenses/by/4.0/). 